\title{
An Approach to Validation of Fuzzy Qualitative Temporal Relations
}

\author{
Slobodan Ribarić, Bojana Dalbelo Bašić and Lada Maleš ${ }^{1}$ \\ Faculty of Electrical Engineering and Computing, University of Zagreb, Croatia \\ ${ }^{1}$ Faculty of Natural Science, Mathematics and Education, Split, Croatia
}

\begin{abstract}
A geometrical approach to validation of fuzzy temporal relations between fuzzy time primitives, based on the possibility and necessity measures are proposed. Fuzzy temporal relations between fuzzy time points and fuzzy time point and fuzzy time interval are considered. The same approach can be used for evaluation of relation between two fuzzy intervals. An example of validation of temporal relations between a fuzzy time point and fuzzy time interval is given.
\end{abstract}

Keywords: fuzzy temporal knowledge, fuzzy temporal relations, necessity and possibility measures.

\section{Introduction}

Research interest in modelling and implementing a technical system that can exhibit some aspects of human intelligence has led to developing various kinds of knowledge representations and reasoning schemes.

As the notion of time is one of the most important aspects of human intelligence, an effort to formalize temporal reasoning process has gained much attention of the artificial intelligence community from the very beginning. It is out of the scope of this paper to give an extensive overview of the proposed temporal models but here are some of them, given in chronological order, that are also relevant for this paper. The time specialist [6], interval-based temporal logic [1], formal logic of plans [7], time maps [3], temporal constraint networks [4], Petri nets with time concepts $[8],[12],[15]$, etc. The fact that human knowledge about time is usually incomplete, pervaded with uncertainty and vagueness and expressed by vague linguistic terms, has made various kinds of representation and reasoning schemes necessary for dealing with vague, incomplete temporal information.

The fuzzy set theory [13] and the possibility theory [14] established by Zadeh represent a very convenient framework for dealing with fuzzy temporal knowledge and are applied in [2], [5], [10] and [11].

Following the idea of building a model capable of effectively reasoning about time in vague environment, just as humans successfully do in every day life, we focus our research interest on the following issues:

- representational capabilities of the model have to include vague linguistic term concerning both, fuzzy time point and fuzzy time interval (e.g. "about five o'clock", "approximately between six and eight o' clock"), and

- the reasoning process has to include qualitative temporal relations between time points and time intervals (e.g. "before the beginning of the meeting", "during the meeting", "after the meeting" etc.).

In order to fulfill the above demands we have proposed geometrical approach for validation of fuzzy qualitative temporal relations [1], based on the possibility and necessity measures [5], [16].

The paper is organized as follows. In Section 2 basic definitions, a description of fuzzy temporal relations and a geometrical approach to validation of possibility and necessity measures are given.

Section 3 deals with validation of fuzzy qualitative temporal relations between fuzzy time 
points, and fuzzy time point and fuzzy time interval. An example of validation process is given in Section 4.

\section{Reasoning with Fuzzy Temporal Knowledge}

\subsection{Basic Definitions}

In this section some basic fuzzy set theory definitions [13], [14], used in this paper, are given.

The fuzzy set $\mathbf{A}$ on the universal set $U$ is the function $\mu_{\mathbf{A}}: U \rightarrow[0,1]$, so that $\mu_{\mathbf{A}}(x)$ represents the degree of membership of the element $x \in U$ to the fuzzy set $\mathbf{A}$. The height of $\mathbf{A}$ is $\operatorname{hgt}(\mathbf{A})=\sup _{x \in U} \mu_{\mathbf{A}}(x)$. It is said that a fuzzy set is normal iff $\operatorname{hgt}(\mathbf{A})=1$. Support and core of $\mathbf{A}$ are crisp sets, defined by $\operatorname{supp}(\mathbf{A})=\left\{x \in U \mid \mu_{\mathbf{A}}(x)>0\right\}$ and core $(\mathbf{A})=$ $\left\{x \in U \mid \mu_{\mathbf{A}}(x)=1\right\}$, respectively. If $\mathbf{A}$ is triangular normal fuzzy set the cardinality of core $(\mathbf{A})$ is 1 .

The time point (or time instant) is a time primitive and it describes an event, the beginning or end of some action/state. The fuzzy time point will be denoted by $\mathbf{a}, \mathbf{b}, \mathbf{c}$, etc. The knowledge about the time point $\mathbf{a}$ is presented in the form of a possibility distribution function $\pi_{\mathbf{a}}$ [5]. The possibility distribution is a function $\pi_{\mathbf{a}}: T \rightarrow[0,1]$, so that $\forall t \in T, \pi_{\mathbf{a}}(t) \in[0,1]$ is a numerical estimate of the possibility that the time point $\mathbf{a}$ is precisely $t$. Possibility distribution is associated with the fuzzy set $\mathbf{A}$ (more or less possible values of $\mathbf{a}$ ) and $\pi_{\mathbf{a}}(t)$ is by definition equal to $\mu_{\mathbf{a}}(t)$ [14]. In this paper fuzzy time points are represented by triangular possibility distributions.

The duration of an action or a state is described by fuzzy time interval. Dubois and Prade [5] have described fuzzy interval as a pair of fuzzy sets: $] \mathbf{A}, \mathbf{B}[$ and $[\mathbf{A}, \mathbf{B}]$. The set $] \mathbf{A}, \mathbf{B}[$ is a set of time points that are more or less certainly between $\mathbf{a}$ and $\mathbf{b}$, and the set $[\mathbf{A}, \mathbf{B}]$ is a set of time points possible between $\mathbf{a}$ and $\mathbf{b}$. These sets are given by:

$$
\begin{aligned}
\mu_{[\mathbf{A}, \mathbf{B}]}(t) & =\sup _{s \leq t \leq s^{\prime}} \min \left(\pi_{\mathbf{a}}(s), \pi_{\mathbf{b}}\left(s^{\prime}\right)\right)= \\
& =[\mathbf{A},+\infty) \cap(-\infty, \mathbf{B}], \\
\mu_{[\mathbf{A}, \mathbf{B}]}(t) & =\min \left(\mu_{] \mathbf{A},+\infty)}(t), \mu_{(-\infty, \mathbf{B}[}(t)\right)= \\
& =[-\infty, \mathbf{A}]^{C} \cap[\mathbf{B},+\infty)^{C},
\end{aligned}
$$

\subsection{Fuzzy Temporal Relations}

In this paper fuzzy temporal relations between two fuzzy time points, fuzzy time point and fuzzy time interval and two fuzzy time intervals are estimated. Relations between fuzzy time points are: before, after and equal. There are five temporal relations between the fuzzy time point and the fuzzy time interval [9]: before, after, during, start and finish. For two fuzzy time intervals there are thirteen possible ways in which they can be related: before, during, start, finish, overlap, equal and their inversion (except to the relation equal) [1]. The fuzzified version of relations between two fuzzy intervals is given by Dubois and Prade [5]. Fuzzy temporal relations are described by possibility and necessity measures.

\subsection{Possibility and Necessity Computation}

The fuzzy set $[\mathbf{A}, \mathbf{B}]$ is obtained as the intersection of fuzzy sets $[\mathbf{A}, \infty)$ and $(-\infty, \mathbf{B}]$.

$[\mathbf{A}, \infty)$ is a fuzzy set of time points that are possible after the point $\mathbf{a}$, and $(-\infty, \mathbf{B}]$ is a fuzzy set of time points that are possible before the point $\mathbf{b}$.

Using those definitions Zhou et al. [16] have proposed geometrical approach to the possibility computation of elementary temporal relation $\mathbf{a} \leq \mathbf{b}$ :

$$
\Pi(\mathbf{a} \leq \mathbf{b})=\frac{\operatorname{Area}([\mathbf{A}, \mathbf{B}]) \cap \pi_{a}}{\operatorname{Area}\left(\pi_{a}\right)}
$$

We have used measure $\Pi(\mathbf{a} \leq \mathbf{b})$ as a primitive for the estimation of all fuzzy temporal relations.

Evaluation process for $\Pi(\mathbf{a} \leq \mathbf{b})$ depends on the relative position of $\pi_{a}$ and $\pi_{b}$ on the time scale.

In order to reduce computational time, existence of the intersection between supports of $\pi_{a}$ and $\pi_{b}$ has to be determined.

If $\operatorname{supp}\left(\pi_{a}\right) \cap \operatorname{supp}\left(\pi_{b}\right) \neq \emptyset$, then $0<\Pi(\mathbf{a} \leq \mathbf{b})$ $\leq 1$ has to be computed. 
If $\operatorname{supp}\left(\pi_{a}\right) \cap \operatorname{supp}\left(\pi_{b}\right)=\emptyset$ then $\Pi(\mathbf{a}<\mathbf{b})$ is equal 0 or 1 .

The computation process of Eq. (1) when $\operatorname{core}(\mathbf{A})>\operatorname{core}(\mathbf{B})$, and $\operatorname{supp}\left(\pi_{a}\right) \cap \operatorname{supp}\left(\pi_{b}\right)$ $\neq \emptyset$ is illustrated in Fig. 1.

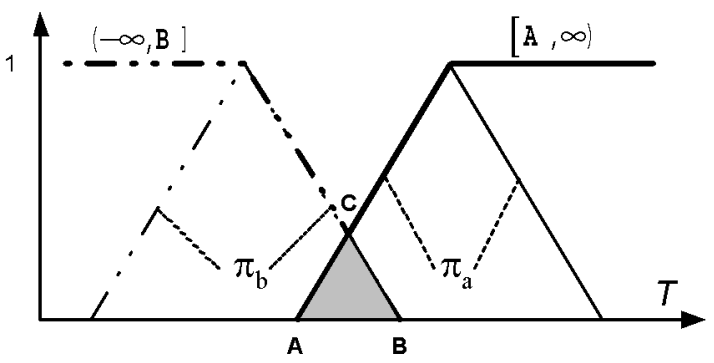

$$
\begin{aligned}
\Pi(\mathbf{a} \leq \mathbf{b}) & =\frac{\operatorname{Area}\left(\text { triangle }_{A B C} \cap \pi_{a}\right)}{\operatorname{Area}\left(\pi_{a}\right)} \\
& =\frac{\operatorname{Area}\left(\operatorname{triangle}_{A B C}\right)}{\operatorname{Area}\left(\pi_{a}\right)}
\end{aligned}
$$

Fig. 1. An illustration of the computation process of the Eq. (1).

For the complete information about temporal relation $\mathbf{a} \leq \mathbf{b}$, besides the possibility measure $\Pi$, the necessity measure $\mathrm{N}$ has to be introduced. Due to the duality between possibility and necessity measures, the necessity measure $[5]$ is defined by $\mathrm{N}(\mathbf{a} \leq \mathbf{b})=1-\Pi(\mathbf{b}<\mathbf{a})$.

Values of possibility and necessity measures for different positions of $\pi_{a}$ and $\pi_{b}$ on time scale are shown on Fig. 2.

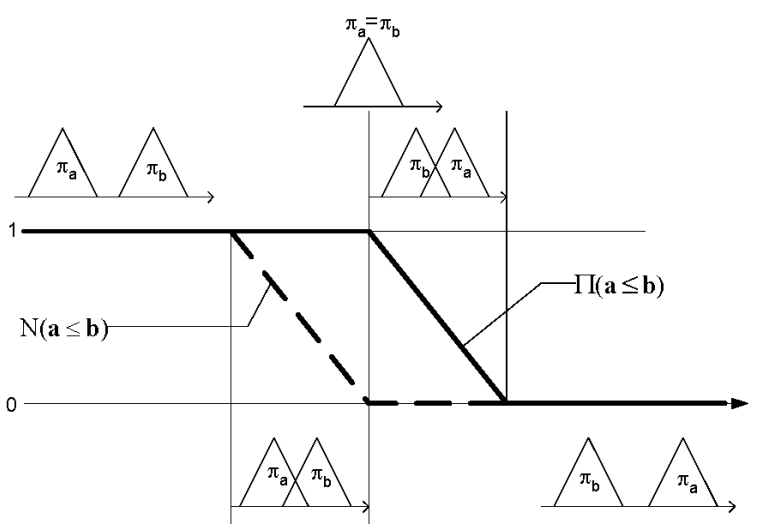

Fig. 2. Values of possibility and necessity measures for different positions of $\pi_{a}$ and $\pi_{b}$.
3. Temporal Relations Between Fuzzy Time Primitives

\subsection{Temporal Relations Between Fuzzy Time Points}

Let $\mathbf{a}$ and $\mathbf{b}$ denote two fuzzy time points described by possibility distributions $\pi_{a}$ and $\pi_{b}$. Possible temporal relations between them are: $\mathbf{a}$ before $\mathbf{b}, \mathbf{a}$ after $\mathbf{b}$ and $\mathbf{a}$ equals $\mathbf{b}$.

\subsubsection{Temporal Relations: a before/after b}

In order to validate temporal relations a $b e$ fore/after $\mathbf{b}$, the intersection between supports of $\pi_{a}$ and $\pi_{b}$ is evaluated and two cases are considered:

(i) $\operatorname{supp}\left(\pi_{a}\right) \cap \operatorname{supp}\left(\pi_{b}\right)=\emptyset$, and

(ii) $\operatorname{supp}\left(\pi_{a}\right) \cap \operatorname{supp}\left(\pi_{b}\right) \neq \emptyset$.

In the case (i) there are two options (see Fig.2):

1) $\Pi(\mathbf{a}<\mathbf{b})=1$ and $N(\mathbf{a}<\mathbf{b})=1$ (see Fig. 3),

2) $\Pi(\mathbf{a}<\mathbf{b})=0$ and $N(\mathbf{a}<\mathbf{b})=0$ (see Fig. 4$)$.

In the case (ii) there are also two options (see Fig. 2):

1) $\Pi(\mathbf{a} \leq \mathbf{b})=1$ and $0<\mathrm{N}(\mathbf{a}<\mathbf{b}) \leq 1$ (see Fig. 5),

2) $0<\Pi(\mathbf{a} \leq \mathbf{b}) \leq 1$ and $N(\mathbf{a} \leq \mathbf{b})=0$ (see Fig. 6).

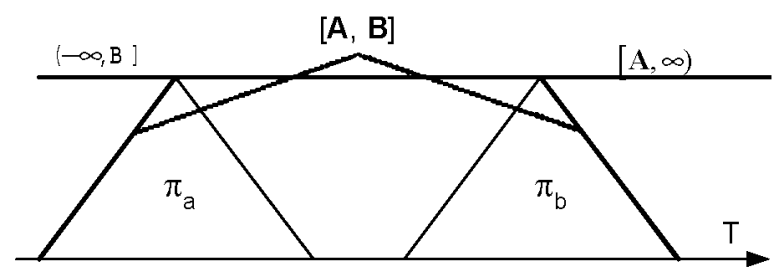

Fig. 3. $\Pi(\mathbf{a}<\mathbf{b})=1, \Pi(\mathbf{a}=\mathbf{b})=0 ; \mathrm{N}(\mathbf{a}<\mathbf{b})=1$, $\mathrm{N}(\mathbf{a}=\mathbf{b})=0$.

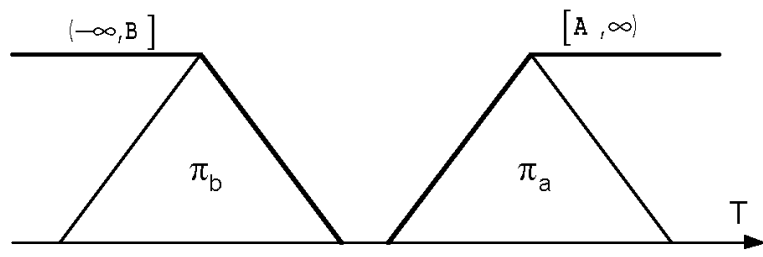

Fig. 4. $\Pi(\mathbf{a}<\mathbf{b})=0, \Pi(\mathbf{a}=\mathbf{b})=0 ; \mathrm{N}(\mathbf{a}<\mathbf{b})=0$, $\mathrm{N}(\mathbf{a}=\mathbf{b})=0$. 


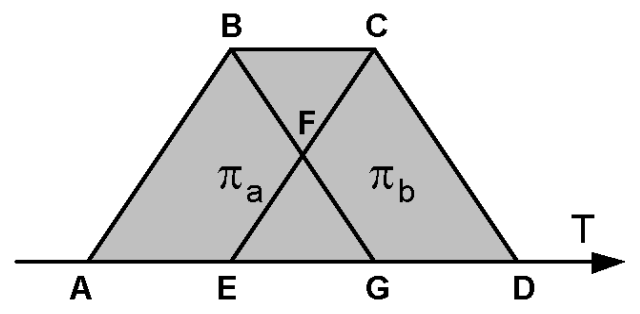

$$
\begin{aligned}
\Pi(\mathbf{a} \leq \mathbf{b}) & =\frac{\operatorname{Area}\left(\operatorname{trapezoid}_{A B C D} \cap \pi_{a}\right)}{\operatorname{Area}\left(\pi_{a}\right)}= \\
& =\frac{\operatorname{Area}\left(\pi_{a}\right)}{\operatorname{Area}\left(\pi_{a}\right)}=1 \\
\Pi(\mathbf{a} \leq \mathbf{b}) & =1-\Pi(\mathbf{a}<\mathbf{b})= \\
& =1-\frac{\operatorname{Area}\left(\operatorname{triangle} E_{E F G} \cap \pi_{b}\right)}{\operatorname{Area}\left(\pi_{b}\right)}= \\
& =1-\frac{\operatorname{Area}\left(\operatorname{triangle} l_{E F G}\right)}{\operatorname{Area}\left(\pi_{b}\right)}
\end{aligned}
$$

Fig. 5. $\Pi(\mathbf{a} \leq \mathbf{b})=1 ; 0<\mathrm{N}(\mathbf{a} \leq \mathbf{b}) \leq 1$.

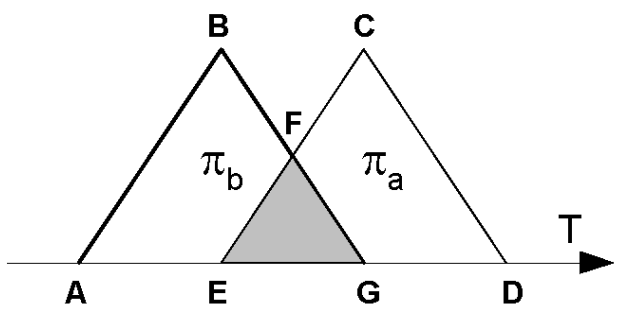

$$
\begin{aligned}
\Pi(\mathbf{a} \leq \mathbf{b}) & =\frac{\operatorname{Area}\left(\text { triangle }_{E F G} \cap \pi_{a}\right)}{\operatorname{Area}\left(\pi_{a}\right)}= \\
& =\frac{\operatorname{Area}\left(\operatorname{triangle}_{E F G}\right)}{\operatorname{Area}\left(\pi_{a}\right)} \\
\mathrm{N}(\mathbf{a} \leq \mathbf{b}) & =1-\Pi(\mathbf{a}<\mathbf{b})= \\
& =1-\frac{\operatorname{Area}\left(\operatorname{trapezoid}_{A B C D} \cap \pi_{b}\right)}{\operatorname{Area}\left(\pi_{b}\right)}= \\
& =1-\frac{\operatorname{Area}\left(\operatorname{trapezoid}_{A B C D}\right)}{\operatorname{Area}\left(\pi_{b}\right)}=1-1=0
\end{aligned}
$$

Fig. 6. $0<\Pi(\mathbf{a} \leq \mathbf{b}) \leq 1 ; \mathrm{N}(\mathbf{a} \leq \mathbf{b})=0$.

The process of validation for the case (ii), option 1 and option 2 are depicted in Fig. 5 and Fig. 6, respectively.

\subsubsection{Temporal Relation a equals b}

If $\operatorname{supp}\left(\pi_{a}\right) \cap \operatorname{supp}\left(\pi_{b}\right)=\emptyset$, then $\Pi(\mathbf{a}=\mathbf{b})=0$ and $\mathrm{N}(\mathbf{a}=\mathbf{b})=0$.

If $\operatorname{supp}\left(\pi_{a}\right) \cap \operatorname{supp}\left(\pi_{b}\right) \neq \emptyset$, then $\Pi(\mathbf{a}=\mathbf{b})$ $=\min \{\Pi(\mathbf{a} \leq \mathbf{b}), \Pi(\mathbf{b} \leq \mathbf{a})\}$.

\subsection{Temporal Relations Between Fuzzy Time Point and Fuzzy Time Interval}

Let $\left[\mathbf{a}_{b}, \mathbf{a}_{e}\right]$ denote the fuzzy interval $\mathbf{A}$, where $\mathbf{a}_{b}$ and $\mathbf{a}_{e}$ are triangular fuzzy numbers $\mathbf{a}_{b}=$ $\left(a_{b 1}, a_{b 2}, a_{b 3}\right)$ and $\mathbf{a}_{e}=\left(a_{e 1}, a_{e 2}, a_{e 3}\right)$ that describe the beginning and the end of fuzzy interval respectively (see Fig. 7). Let tp denote fuzzy time point (see Fig. 8). Possibility distributions $\pi_{b, a}$ and $\pi_{e, a}$ are of the beginning and the end of the interval A. As we have already mentioned, there are five temporal relations between the fuzzy time point tp and the fuzzy time interval $\mathbf{A}$.

We can estimate the degrees of possibility and necessity for temporal relations between fuzzy time point and the fuzzy time interval.

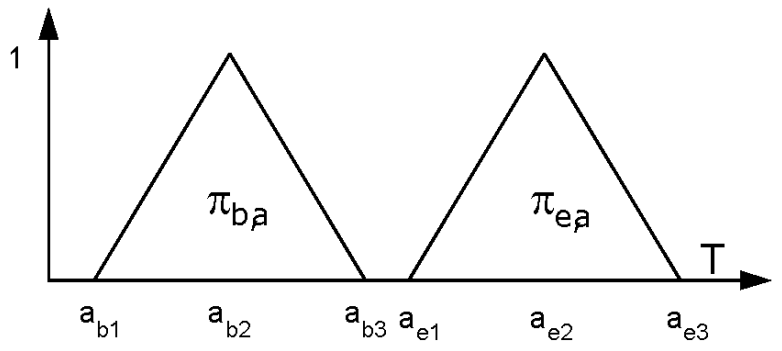

Fig. 7. Fuzzy numbers $\mathbf{a}_{b}$ and $\mathbf{a}_{e}$.

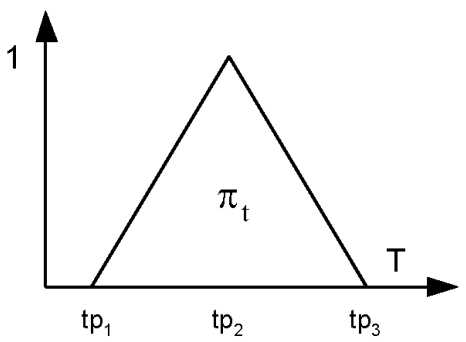

Fig. 8. Fuzzy number tp. 


\subsubsection{Before}

$\Pi(\mathbf{t p}$ before $\mathbf{A})=\Pi\left(\mathbf{t p}<\mathbf{a}_{b}\right)$ and

$\mathrm{N}(\mathbf{t p}$ before $\mathbf{A})=\mathrm{N}\left(\mathbf{t p}<\mathbf{a}_{b}\right)$.

If $\operatorname{supp}\left(\pi_{t p}\right) \cap \operatorname{supp}\left(\pi_{b, a}\right)=\emptyset$ then

$$
\Pi\left(\mathbf{t p}<\mathbf{a}_{b}\right)= \begin{cases}1, & \forall t \in\left[t p_{1}, t p_{3}\right] \text { less } \\ & \text { than } \forall t \in\left[a_{b 1}, a_{b 3}\right] \\ 0, & \forall t \in\left[t p_{1}, t p_{3}\right] \text { greater } \\ & \text { than } \forall t \in\left[a_{b 1}, a_{b 3}\right]\end{cases}
$$

and

$$
\mathbf{N}\left(\mathbf{t p}<\mathbf{a}_{b}\right)= \begin{cases}1, & \forall t \in\left[t p_{1}, t p_{3}\right] \text { less } \\ & \text { than } \forall t \in\left[a_{b 1}, a_{b 3}\right] \\ 0, & \forall t \in\left[t p_{1}, t p_{3}\right] \text { greater } \\ & \text { than } \forall t \in\left[a_{b 1}, a_{b 3}\right]\end{cases}
$$

If $\operatorname{supp}\left(\pi_{t p}\right) \cap \operatorname{supp}\left(\pi_{b, a}\right) \neq \emptyset$ then $0<\Pi(\mathbf{t p} \leq$ $\left.\mathbf{a}_{b}\right) \leq 1$ and $0 \leq \mathrm{N}\left(\mathbf{t p} \leq \mathbf{a}_{b}\right)<1$ (see Fig. 5 . and Fig. 6.).

\subsubsection{After}

$\Pi(\mathbf{t p}$ after $\mathbf{A})=\Pi\left(\mathbf{a}_{e}<\mathbf{t p}\right)$ and

$\mathrm{N}(\mathbf{t p}$ after $\mathbf{A})=\mathrm{N}\left(\mathbf{a}_{e} \leq \mathbf{t p}\right)$.

If $\operatorname{supp}\left(\pi_{t p}\right) \cap \operatorname{supp}\left(\pi_{e, a}\right)=\emptyset$ then

$$
\Pi\left(\mathbf{a}_{e}<\mathbf{t p}\right)= \begin{cases}1, & \forall t \in\left[a_{e 1}, a_{e 3}\right] \text { less } \\ & \text { than } \forall t \in\left[t p_{1}, t p_{3}\right] \\ 0, & \forall t \in\left[a_{e 1}, a_{e 3}\right] \text { greater } \\ & \text { than } \forall t \in\left[t p_{1}, t p_{3}\right]\end{cases}
$$

and

$$
\mathrm{N}\left(\mathbf{a}_{e}<\mathbf{t p}\right)= \begin{cases}1, & \forall t \in\left[a_{e 1}, a_{e 3}\right] \text { less } \\ & \text { than } \forall t \in\left[t p_{1}, t p_{3}\right] \\ 0, & \forall t \in\left[a_{e 1}, a_{e 3}\right] \text { greater } \\ & \text { than } \forall t \in\left[t p_{1}, t p_{3}\right]\end{cases}
$$

If $\operatorname{supp}\left(\pi_{t p}\right) \cap \operatorname{supp}\left(\pi_{e, a}\right) \neq \emptyset$ then $0<\Pi\left(\mathbf{a}_{e} \leq\right.$ tp) $\leq 1$ and $0 \leq \mathrm{N}\left(\mathbf{a}_{e} \leq\right.$ tp $)<1$ (see Fig. 5 . and Fig. 6.).

\subsubsection{During}

$\Pi(\mathbf{t p}$ during $\mathbf{A})=\min \left\{\Pi\left(\mathbf{a}_{b}<\mathbf{t p}\right), \Pi\left(\mathbf{t p}<\mathbf{a}_{e}\right)\right\}$ and
$\mathrm{N}($ tp during $\mathbf{A})=\min \left\{\mathrm{N}\left(\mathbf{a}_{b} \leq \mathbf{t p}\right), \mathrm{N}\left(\mathbf{t p} \leq \mathbf{a}_{e}\right)\right\}$.

If $\operatorname{supp}\left(\pi_{t p}\right) \cap \operatorname{supp}\left(\pi_{b, a}\right)=\emptyset$ then

$$
\Pi\left(\mathbf{a}_{b}<\mathbf{t p}\right)= \begin{cases}1, & \forall t \in\left[a_{b 1}, a_{b 3}\right] \text { less } \\ & \text { than } \forall t \in\left[t p_{1}, t p_{3}\right] \\ 0, & \forall t \in\left[a_{b 1}, a_{b 3}\right] \text { greater } \\ & \text { than } \forall t \in\left[t p_{1}, t p_{3}\right]\end{cases}
$$

and

$$
\mathrm{N}\left(\mathbf{a}_{b}<\mathbf{t p}\right)= \begin{cases}1, & \forall t \in\left[a_{b 1}, a_{b 3}\right] \text { less } \\ & \text { than } \forall t \in\left[t p_{1}, t p_{3}\right] \\ 0, & \forall t \in\left[a_{b 1}, a_{b 3}\right] \text { greater } \\ & \text { than } \forall t \in\left[t p_{1}, t p_{3}\right]\end{cases}
$$

If $\operatorname{supp}\left(\pi_{t p}\right) \cap \operatorname{supp}\left(\pi_{b, a}\right) \neq \emptyset$ then $0<\Pi\left(\mathbf{a}_{b} \leq\right.$ tp) $\leq 1$ and $0 \leq \mathrm{N}\left(\mathbf{a}_{b} \leq \mathbf{t p}\right)<1$ (see Fig. 5 . and Fig. 6.).

If $\operatorname{supp}\left(\pi_{t p}\right) \cap \operatorname{supp}\left(\pi_{e, a}\right)=\emptyset$ then

$$
\Pi\left(\mathbf{t p}<\mathbf{a}_{e}\right)= \begin{cases}1, & \forall t \in\left[t p_{1}, t p_{3}\right] \text { less } \\ & \text { than } \forall t \in\left[a_{e 1}, a_{e 3}\right] \\ 0, & \forall t \in\left[t p_{1}, t p_{3}\right] \text { greater } \\ & \text { than } \forall t \in\left[a_{e 1}, a_{e 3}\right]\end{cases}
$$

and

$$
\mathrm{N}\left(\mathbf{t p}<\mathbf{a}_{e}\right)= \begin{cases}1, & \forall t \in\left[t p_{1}, t p_{3}\right] \text { less } \\ & \text { than } \forall t \in\left[a_{e}, a_{e 3}\right] \\ 0, & \forall t \in\left[t p_{1}, t p_{3}\right] \text { greater } \\ & \text { than } \forall t \in\left[a_{e}, a_{e 3}\right]\end{cases}
$$

If $\operatorname{supp}\left(\pi_{t p}\right) \cap \operatorname{supp}\left(\pi_{e, a}\right) \neq \emptyset$ then $0<\Pi(\mathbf{t p} \leq$ $\left.\mathbf{a}_{e}\right) \leq 1$ and $0 \leq \mathrm{N}\left(\mathbf{t p}_{b} \leq \mathbf{a}_{e}\right)<1$ (see Fig. 5 . and Fig. 6.).

\subsubsection{Starts}

$\Pi(\mathbf{t p}$ starts $\mathbf{A})=\Pi\left(\mathbf{t p}=\mathbf{a}_{b}\right)$ and

$\mathrm{N}($ tp starts $\mathbf{A})=\mathrm{N}\left(\mathbf{t p}=\mathbf{a}_{b}\right)$.

If $\operatorname{supp}\left(\pi_{t p}\right) \cap \operatorname{supp}\left(\pi_{b, a}\right)=\emptyset$ then $\Pi\left(\mathbf{t p}=\mathbf{a}_{b}\right)=0$ and $\mathrm{N}\left(\mathbf{t p}=\mathbf{a}_{b}\right)=0$.

If $\operatorname{supp}\left(\pi_{t p}\right) \cap \operatorname{supp}\left(\pi_{b, a}\right) \neq \emptyset$ then $0<\Pi\left(\mathbf{t p} \leq \mathbf{a}_{b}\right) \leq 1$ and $0 \leq \mathrm{N}\left(\mathbf{t p} \leq \mathbf{a}_{b}\right)<1$ (see Fig. 5. and Fig. 6.). 


\subsubsection{Finishes}

$\Pi(\mathbf{t p}$ finishes $\mathbf{A})=\Pi\left(\mathbf{t p}=\mathbf{a}_{e}\right)$ and

$\mathrm{N}(\mathbf{t p}$ finishes $\mathbf{A})=\mathrm{N}\left(\mathbf{t p}=\mathbf{a}_{e}\right)$.

If $\operatorname{supp}\left(\pi_{t p}\right) \cap \operatorname{supp}\left(\pi_{e, a}\right)=\emptyset$ then $\Pi(\mathbf{t p}=$ $\left.\mathbf{a}_{e}\right)=0$ and $\mathrm{N}\left(\mathbf{t p}=\mathbf{a}_{e}\right)=0$.

If $\operatorname{supp}\left(\pi_{t p}\right) \cap \operatorname{supp}\left(\pi_{e, a}\right) \neq \emptyset$ then $0<\Pi(\mathbf{t p} \leq$ $\left.\mathbf{a}_{e}\right) \leq 1$ and $0 \leq \mathrm{N}\left(\mathbf{t p} \leq \mathbf{a}_{e}\right)<1$ (see Fig. 5 . and Fig. 6.).

\section{Example}

Based on the discussion in the previous sections we give a simple example of the validation process of all temporal relations between fuzzy time point and fuzzy time interval.

John's meeting starts at about 10 o'clock and finishes about 12 o'clock. He expects an important telephone call that is announced at about 10.15 .

The knowledge about John's meeting is defined by two possibility distributions $\pi_{b, a}$ and $\pi_{e, a}$ representing the possible starting and ending times of John's meeting, respectively. Possibility distributions $\pi_{b, a}=(9: 30,10: 00,10: 30)$ and $\pi_{e, a}=(11: 30,12: 00,12: 30)$ are depicted in Fig. 9. The knowledge about the time point representing the possible time of an important telephone call, about 10.15 , is given by the possibility distribution $\pi_{t p}=(9: 45,10: 15,10$ : 45) (see Fig. 9).

In this example we want to compute possibility and necessity measures for five temporal relations between fuzzy time point (time of an important telephone call) and fuzzy time interval (duration of John's meeting).

The intersections between possibility distributions supports are examined first.

$\operatorname{Because} \operatorname{supp}\left(\pi_{t p}\right) \cap \operatorname{supp}\left(\pi_{e, a}\right)=\emptyset$, possibility and necessity measures are:

$\Pi\left(\mathbf{t p}=\mathbf{a}_{e}\right)=0$ and $\mathrm{N}\left(\mathbf{t p}=\mathbf{a}_{e}\right)=0$,

$\Pi\left(\mathbf{t p}<\mathbf{a}_{e}\right)=1$ and $\mathrm{N}\left(\mathbf{t p}<\mathbf{a}_{e}\right)=1$

and for the inverse relations:

$\Pi\left(\mathbf{a}_{e}<\mathbf{t p}\right)=0$ and $\mathrm{N}\left(\mathbf{a}_{e}<\mathbf{t p}\right)=0$.

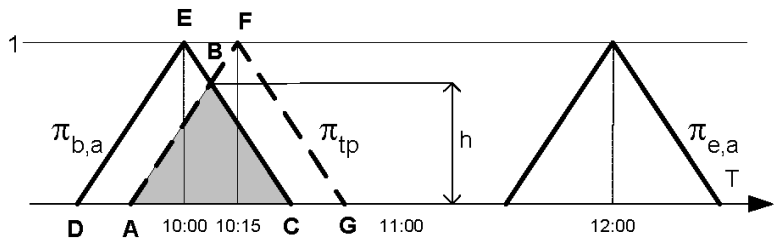

Fig. 9. Possibility distributions $\pi_{b, a}$ and $\pi_{e, a}$ (representing the start and the end of fuzzy interval) and $\pi_{t p}$ (representing the time point).

Since $\operatorname{supp}\left(\pi_{a}\right) \cap \operatorname{supp}\left(\pi_{b}\right) \neq \emptyset$ measures $\Pi(\mathbf{t p} \leq$ $\left.\mathbf{a}_{b}\right), \Pi\left(\mathbf{a}_{b} \leq \mathbf{t p}\right), \mathrm{N}\left(\mathbf{t p} \leq \mathbf{a}_{b}\right)$ and $\mathrm{N}\left(\mathbf{a}_{b} \leq \mathbf{t p}\right)$ are computed as follows:

$$
\begin{aligned}
\Pi\left(\mathbf{t p} \leq \mathbf{a}_{b}\right) & =\frac{\operatorname{Area}\left(\operatorname{triangle}_{A B C} \cap \pi_{t p}\right)}{\operatorname{Area}\left(\pi_{t p}\right)}= \\
& =\frac{\operatorname{Area}\left(\operatorname{triangle}_{A B C}\right)}{\operatorname{Area}\left(\pi_{t p}\right)}=\frac{\frac{45 \cdot h}{2}}{\frac{60 \cdot 1}{2}}= \\
& =\frac{3}{4} \cdot h=\frac{3}{4} \cdot \frac{3}{4}=\frac{9}{16}=0.5625
\end{aligned}
$$

(where $h$ represents the height of the triangle ${ }_{A B C}$ ).

$$
\begin{aligned}
\Pi\left(\mathbf{a}_{b} \leq \mathbf{t p}\right) & =\frac{\operatorname{Area}\left(\operatorname{trapezoid}_{D E F G} \cap \pi_{b, a}\right)}{\operatorname{Area}\left(\pi_{b, a}\right)}= \\
& =\frac{\operatorname{Area}\left(\pi_{b, a}\right)}{\operatorname{Area}\left(\pi_{b, a}\right)}=1 \\
\mathrm{~N}\left(\mathbf{t p} \leq \mathbf{a}_{b}\right) & =1-\Pi\left(\mathbf{a}_{b} \leq \mathbf{t p}\right)=1-1=0 \\
\mathrm{~N}\left(\mathbf{a}_{b} \leq \mathbf{t p}\right) & =1-\Pi\left(\mathbf{t p} \leq \mathbf{a}_{b}\right)= \\
& =1-0.5625=0.4375
\end{aligned}
$$

These measures are used to estimate the degree of possibility and necessity for all temporal relations between the time of telephone call and the time of meeting:

$\Pi(\mathbf{t p}$ before $\mathbf{A})=\Pi\left(\mathbf{t p} \leq \mathbf{a}_{b}\right)=0.5625$,

$\mathrm{N}(\mathbf{t p}$ before $\mathbf{A})=\mathrm{N}\left(\mathbf{t p} \leq \mathbf{a}_{b}\right)=0$,

$\Pi(\mathbf{t p}$ after $\mathbf{A})=\Pi\left(\mathbf{a}_{e}<\mathbf{t p}\right)=0$,

$N(\mathbf{t p}$ after $\mathbf{A})=\mathrm{N}\left(\mathbf{a}_{e}<\mathbf{t p}\right)=0$,

$\Pi(\mathbf{t p}$ during $\mathbf{A})=\min \left\{\Pi\left(\mathbf{a}_{b} \leq \mathbf{t p}\right), \Pi\left(\mathbf{t p}<\mathbf{a}_{e}\right)\right\}=1$,

$\mathrm{N}(\mathbf{t p}$ during $\mathbf{A})=\min \left\{\mathrm{N}\left(\mathbf{a}_{b} \leq \mathbf{t p}\right), \mathrm{N}\left(\mathbf{t p}<\mathbf{a}_{e}\right)\right\}=$

$$
=\min \{0.4375,1\}=0.4375 \text {, }
$$

$\Pi(\mathbf{t p}$ starts $\mathbf{A})=\Pi\left(\mathbf{t p}=\mathbf{a}_{b}\right)=0.5625$,

$\mathrm{N}($ tp starts $\mathbf{A})=\mathrm{N}\left(\mathbf{t p}=\mathbf{a}_{b}\right)=0$, 
$\Pi(\mathbf{t p}$ finishes $\mathbf{A})=\Pi\left(\mathbf{t p}=\mathbf{a}_{e}\right)=0$,

$\mathrm{N}(\mathbf{t p}$ finishes $\mathbf{A})=\mathrm{N}\left(\mathbf{t p}=\mathbf{a}_{e}\right)=0$.

According to these results it is completely possible that the telephone call occurs during the meeting. The necessity for relation during is 0.4375 . Also, it is possible that the telephone call occurs before or at the beginning of the meeting with the possibility 0.5625 , but these temporal relations are not certain. All other relations are not possible.

\section{Conclusion}

In this paper we have introduced geometrical approach to validation of the possibility and necessity measures for temporal relations between two fuzzy time points and a fuzzy time point and a fuzzy time interval. Measures are based on proportions of areas given by Eq. 1. In order to simplify the validation process all temporal relations are represented by triangular and/or trapezoidal fuzzy numbers. The possibility and necessity measures for temporal relations between fuzzy time intervals can be computed in the same way.

Fuzzy temporal reasoning introduced in this paper represents a base for building adequate models for temporal knowledge representation and reasoning in environments where time is described as fuzzy, unprecize and vague.

\section{References}

[1] ALLEN JF. Maintaining knowledge about temporal intervals. Communications of ACM 1983; 26(11):832-843.

[2] Barro S., Marin R., Mira J., PATON AR. Model and Language for the Fuzzy Representation and handling of Time. Fuzzy Sets and System 1994; 61(2):153-175.

[3] DeAn TL., McDermott DV. Temporal Data Base Management. Artificial Intelligence 1991; 32:1-55.

[4] Dechter R., Meiri I., PeARl J. Temporal Constraint. Artificial Intelligence 1991; 49:61-95.

[5] Dubois D., Prade H. Processing Fuzzy Temporal Knowledge. IEEE Transaction on System, Man and Cybernetics 1989; 19(4):729-744.

[6] KAHN K., GORRY GA. Mechanizing Temporal Knowledge, Artificial Intelligence 1977; 9:87-108.
[7] PelaVin R., Allen JF. A Formal Logic of Plants in Temporally Rich Domains. Proceeding of the IEEE 1986; 74(10):1364-1382.

[8] RIBARIĆ S., DALBElo BAŠIĆ B. Temporal Knowledge Representation and Reasoning Model Based on Petri Nets with Time Tokens. In: Proceedings of the IEEE 8th Mediterranean Electrotechnical Conference, Industrial Applications in Power Systems, Computer Science and Telecommunications, MELECON'96; Bari, Italy, May 13-16, 1996. p. 131-135.

[9] RIBARIĆ S., DALBElo BAŠIĆ B. Modelling Crisp and Fuzzy Qualitative Temporal Relations, In: The Proceedings of the 12th International Conference on Information and Intelligent Systems - IIS 2001, September 26-28; 2001, Varazdin, Croatia, p. 218226.

[10] RiBARIĆ S., DALBElo BAŠIĆ B., TOMAC D. ObjectOriented Implementation of a Model for Fuzzy Temporal Reasoning, Technologies for Constructing Intelligent Systems, Eds. B. Bouchon-Meunier, J. Gutierrez-Rios, L. Magdalena and R.R. Yager, Springer-Verlag, 2002.

[11] Virant J., ZimiC N. Attention to Time in Fuzzy Logic. Fuzzy Sets and Systems (1996), 82: 59-77.

[12] Yao Y. A Petri Net Model for Temporal Knowledge Representation and Reasoning. IEEE Transaction on System, Man and Cybernetics 1994; 24(9):13741382.

[13] ZADEH LA. Fuzzy sets. Information and Control $1965 ; 8(4): 338-353$.

[14] ZADEH LA. Fuzzy sets as a Basis for Theory of Possibility. Fuzzy Sets and Systems 1978; 1:3-28.

[15] ZAIDI AK. On Temporal Logic Programming Using Petri Nets. IEEE Transaction on System, Man and Cybernetics 1999; 29(3):245-254.

[16] Zhou Y., Murata T., DeFanti TA. Modeling and Performance Analysis Using Extended FuzzyTiming Petri Nets for Networked Virtual Environements. IEEE Transaction on System, Man and Cybernetics 2000; 30(5):737-756.

Received: June, 2002 Accepted: September, 2002

Contact address:

Slobodan Ribarić, Bojana Dalbelo Bašić Faculty of Electrical Engineering and Computing University of Zagreb Unska 3, 10000 Zagreb, Croatia e-mail: $\{$ slobodan.ribaric|bojana.dalbelo\}@fer.hr

Lada Maleš

Faculty of Natural Science Mathematics and Education Nikole Tesle 12, 21000 Split, Croatia e-mail: lada.males@pmfst.hr 
SLOBODAN RIBARIĆ received his B.S. degree in electronics, the M.S. degree in automatics and the $\mathrm{PhD}$. degree in electrical engineering from the Faculty of Electrical Engineering, Ljubljana, Slovenia, in 1974, 1976, and 1982, respectively. He is currently a Full Professor at the Department of Electronics, Microelectronics, Computer and Intelligent Systems, Faculty of Electrical Engineering and Computing, University of Zagreb, Croatia. His research interests include pattern recognition, artificial intelligence, computer architecture and robot vision. He has published more than one hundred and twenty papers on these topics, and he is author of four books (Microprocessor Architecture, The Fifth Computer Generation Architecture, Advanced Microprocessor Architectures, CISC and RISC Computer Architecture) and co-author of one (An Introduction to Pattern Recognition). Dr. Ribarí is a member of the IEEE and IAPR.

BOJANA DALBELo BAŠIĆ received her B.S. degree in mathematics from the Faculty of Sciences, University of Zagreb, in 1982 and the M.S. and $\mathrm{PhD}$. degrees in computer science from the Faculty of Electrical Engineering and Computing, University of Zagreb, in 1993 and 1997, respectively. In 2000 she received a DAAD grant. She has published forty papers, mostly concerning applied multivariate statistics, fuzzy temporal reasoning and intelligent systems. Currently, she is Assistant Professor at the Faculty of Electrical Engineering and Computing, University of Zagreb. Her current research interests include machine learning, especially kernel based methods.

LADA MALEŠ received her B.S. degree in electronics from the Faculty of Electrical Engineering, Mechanical Engineering and Naval Architecture, University of Split, in 1996 and the M.S. degree in computer science from the Faculty of Electrical Engineering and Computing, University of Zagreb, in 2002. Currently, she is an assistant at the Department of Informatics, Faculty of Natural Science, Mathematics and Education, University of Split. Her research interests include fuzzy temporal reasoning and intelligent systems. Lada Malě is a member of the IEEE. 